\title{
Editorial
}

\section{On the manageability of large human systems}

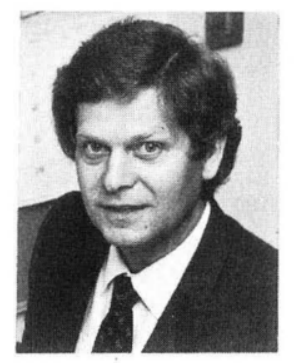

Gerhard O. Mensch is Professor of Management at the Weatherhead School of Management, and Professor of Economics at the Economics department of Case Western Reserve University, after having directed an innovations research group team and an industrial policy analysis group at the International Institute of Management, Science Center Berlin, for ten years. Prior to this, he was associate professor of management science at Tulane University, visiting professor at Bonn University, and visiting scholar at Harvard, Stanford and Berkeley.

$\mathrm{He}$ has published and co-authored several books and numerous articles on macro-economic change, and technological innovation in firms and in regions, being interested in the internal and external conditions of entrepreneurship, innovation and infant industry formation, and the human resource and policy aspects of it. He has been a consultant to industrial corporations and government agencies, and participated in and led action research groups for long-term economic policy (Bonn), regional economic turnaround (Berlin). Currently, at Case in Cleveland, he is helping in building up a teaching and research program in technical innovations management and entrepreneurship (TIME) and regional industry-base analysis.
North-Holland

Human Systems Management 5 (1985) 1-4
1983 is the Schumpeter Year. Economists and social scientists commemorate the hundredth anniversary of Joseph A. Schumpeter, the great Austrian-American political economist, for his towering intellectual achievements, notably for his theory of economic development. It is actually a theory of socio-economic evolution. Schumpeter saw the economy as a process, a Process of Creative Destruction. You cannot make an omelet without cracking an egg. His was a non-equilibrium theory. At any point in time, the socio-economic forces of creation need not equal their counterpart, and the benefits of creation (production, growth, reproduction) need not balance with destruction (cost, loss, obsolescence). In fact, lots of eggs can get cracked without much omelet to emerge. Economic crises. Ungovernability. Unmanageability. These are non-equilibrium phenomena in the Process of Creative Destruction.

Today, Schumpeter's name stands synonymous for the question whether our democratic system can withstand the stresses of economic slump and depression, and can endure the strains and pains of all the readjustments and the restructuring needed for recovery. Can Capitalism Survive? is the title of the second part of Schumpeter's Capitalism, Socialism, and Democracy, which came out in 1942. Schumpeter's insights appear especially useful in times of stagnation, and depression, since it is the tightening of budgets in government agencies and private corporations, and the Social Limits to Growth (Hirsch, 1976), that render nation states 'ungovernable' and institutions 'unmanageable'. Over the last few years, economic decline has thus generated a boom in Schumpeterian economics. "No economist was more sophisticated", said George J. Stigler in his 1982 Nobel Lecture in Stockholm. 
Schumpeter's answer to the question of capitalism's survival was decidedly negative. Two seemingly opposite lines of thought, both with a considerable tradition in Western culture, led him to the same negative conclusion that the days of the capitalistic order are counted, since 'management by delegation' in privately owned corporations, and 'government by objectives' in public service institutions would fail to work well. In essence, Schumpeter believed that either under-creativity or over-destruction will bring the free enterprise system to an end.

The Over-Destruction Thesis builds on the general idea that the free enterprise system is a very strong, dynamical force. Its strength, the profit-seeking drive and private owners' prudence, are considered powerful instruments for attaining certain developmental purposes, notably those emerging in urbanization/industrialization. Guided and checked by the market mechanism's Invisible Hand, capitalism is thought to be the most effective and efficient modus operandi to reach the socio-economic potential attainable to a country, a region, or a community. However, nothing fails like success; near the limits to growth, the Capitalist Process of Creative Destruction turns self-destructive. Examples of this thesis abound. In the steel industry, for example, dispersed ownership of the large corporations means lack of owners' control over management, and hence a decline of profitability. De-emphasis of the profit seeking drive results in collusive management-union relations, which allow productivity to fall and labor cost to rise; often enough in partial response to government regulation and intervention.

Furthermore, and most importantly, the wealth creation power of the capitalist process is seen by Schumpeter to undermine the very philosophical and psychological foundation of the work ethic that makes capitalism a strong force.

On the other hand, The Under-Creativity Thesis is based on the assumption that capitalism is essentially a weak force, very weak in relation to the inertia and resistance to change it must overcome in society. Over the past century, capitalism has been most successful in achieving technological innovations, since they meet with less resistance than political, social or moral innovations, and can be more easily accomplished by private initiative of individual entrepreneurs. In the "higher spheres' of civilization, in the political, social, and moral realms, innovation is more and more beyond the individual.

Hence, in regard to creativity needed for progress in those 'higher spheres', capitalism in this view appears less and less capable of achieving sufficient change for sustained growth. In looking for evidence, various West-European countries exhibit a correlation between the persistence of some feudal practices and aristocratic reglementations on the one hand, and relatively lower material standards of living on the other. By the same token, Marxist economists explain differences in economic performance between East-European COMECON countries by their different degree of success of the 'bourgeois' revolution prior to the 'proletarian'; in other words, by nuances in weakness of the capitalist system in those countries prior to the socialist takeover.

Fully consistent with this Under-Creativity Thesis is poor economic performance in the public goods sectors in the U.S., the 'non-market sectors'. Although no feudal remnants had to be overcome by capitalism, the same formula seems again to hold that the more market orientation prevailed in the construction and maintenance of public roads, bridges, dams, etc., the lower the cost, degree of waste, unreliability, etc. "In other words", writes Albert Hirschman in a recent article in the Journal of Economic Literature (1982), "the trouble with capitalism, suddenly, is not that it is so strong as to be self-destructing but that it is too weak to play the 'progressive' role history has supposedly assigned to it."

Hirschman then remarks on the obvious contradiction in Schumpeter's reasoning: "Strangely enough, Schumpeter therefore became an articulate spokesman - far more so than Marx - both for the feudal-shackles thesis, according to which the trouble with capitalism was its weakness (vis-àvis precapitalist forms), and for the self-destruction thesis which emphasizes capitalism's corrosive strength. To explain this apparent inconsistency it must first be pointed out that the texts which contain the two theses were written over twenty years apart from one another. Second, the two theses, in spite of their contradiction, have various characteristics in common: both underline the importance of ideology and mentality and thereby are self-consciously critical of Marxism; and both take an obvious pleasure in stressing the key role of the irrational in human affairs, once again in 
line with the contemporary intellectual climate due to such figures as Freud, Bergson, Sorel and Pareto."

We have thus arrived at an important conclusion on governability of market societies, and manageability of large organizations in them: The ideological foundation for our institutional order is inconsistent, and does not provide a prior direction for the adjustment restructuring needed for recovery. The usual dichotomy of 'more market' versus 'less market' is an over-simplification. For example, it cannot explain the superiority in productivity of the Japanese corporations. Japanese firms are so successful not in spite of feudal remnants in Japan, but because of them. They give Japanese employers social collateral: parts of the indirect cost of organizing for high productivity are born by the employee's family, by community organizations, and by other social institutions in Japan.

Obviously, the productivity gap in the U.S. cannot be closed by re-inventing feudal practices in order to help industrial corporations externalize labor cost. Nor would a switch to socialist forms of vertical integration promise any productivity gains as long as the inconsistencies hinge upon irrationalities on the level of the individual: the Russian example testifies to the fact that ungovernability and unmanageability are not so much a matter of 'system' and 'regime' but of attitudes, mentalities, motivations, and other micro-social facts. Such facts have to be given higher weight in human systems management, whereas traditional normative macro-sociological beliefs have to be discounted. How?

F.A. Hayek teaches that progress in economic science came step-wise, and each advance was by way of integrating some subjective elements into the body of analytical knowledge. Our conclusion is consistent with Hayek's view. An advance in political and managerial economics would seem to require a redefinition of the micro-sociological foundations of economics. The same point, we now see, has already been made by Schumpeter. How can this requirement be fulfilled?

I think a recent contribution by two German authors, Wolfgang Weidlich and Guenter Haag, provides a constructive specification of the required micro-sociological foundations of economics. Their Concepts and Models of a Quantitative Sociology; The Dynamics of Interacting Populations (Springer,
Berlin, 1983) contains a formal, rather general theory of motion of socio-economic macro-systems, based upon attitudinal changes of collectives of individuals as the micro-social driving forces.

The three fundamental concepts which Weidlich and Haag introduce into quantitative sociology are attitude space, situation space, and socio-configuration. The situation space consists of the dimensions which characterize a situation. A situation is described in terms of economic variables (production, employment, investment, inflation, innovation, capital accumulation, etc.) and other aspects about which individuals form attitudes and expectations.

"For a given situation vector $y$ and under the influence of the psychological constitution of the individuals, there develops a certain attitude distribution or socio-configuration $n(t)$. The motion of $n(t)$ is due to transitions between attitudes caused by individual decision processes. A society with a given socio-configuration $n(t)$ influences and drives the situation vector into new states $y(t)$. For instance, people with certain attitudes develop corresponding activities which change the economic and legislative situation. The changed situation $y(t)$ will in turn react on the socio-configuration $n(t)$. Under simple assumptions, the motion may end in a stable stationary state $\left\{n_{s t}, y_{s t}\right\}$. In general, however, the interactions between $n(t)$ and $y(t)$ will lead to a perpetuated highly complex coupled motion of $n(t)$ and $y(t)$."

According to Weidlich and Haag, the dynamics of interacting populations consist of structural shifts among subpopulations in the socio-configuration, formulated in terms of interdependent equations of motion which obey the general probabilistic laws governing the statistical interactions in multi-component systems. The individual members of society contribute through their cultural and economic activities to the generation of a general field of civilization with cultural, political, religious, social and economic components. This collective field determines the socio-political atmosphere and the cultural and economic standard of the society and may be considered as an order parameter of the system characterizing the phase in which the society exists. Vice versa, the collective field strongly influences the individuals in the society by orientating their attitudes and activities, by activating or de-activating their latent positive and negative qualities and capabilities, and by 
extending or narrowing their scope of thinking and action.

Against this general background of interactions, which are formulated by the system of equations, it becomes understandable when, in what phase and under what order, a certain human system is manageable, and when it becomes unmanageable ('out of order, out of phase', as the saying goes). If the control parameters governing the dynamic behavior of the system attain certain critical values, the macrovariables may move into a critical domain out of which highly divergent alternative paths are possible. In this situation small, unpredictable microfluctuations - for instance, the actions of very few influential people - may decide into which of the diverging paths the behavior of the system will bifurcate. This bifurcation process is called a phase transition. In general terms, a part of a system may become unmanageable, or the whole may become ungovernable under the existing order, if critical values of discrepancies attain, and then it may be that only a phase transition can straighten things out. For human systems management this theory is of great value; it allows to evaluate necessary and sufficient changes in attitude space as determinants of change in the situation.

This formal theory of self-organization of systems is being applied to three important problem areas, in which the lack of substantive theory has been an impediment of policy making.

(1) The problem of out-migration of workers has for years troubled regions such as rural Sicily and urban Northeast Ohio, whereas the immigration regions such as London and California now suffer from overcrowding. Weidlich and Haag show that a combination of rational and irrational attitudes can distort the spatial distribution of two types of people, such as natives and immigrants, and can lead to either stable integration patterns, or severe imbalances, or even turbulent circular flows, if irrationality passes some threshold values.

(2) The problem of under-investment and under-employment, which today is common to nearly all sectors in all Western countries, can be tracked down, in part, to the managerial strategies of industrial corporations. Weidlich and Haag adopt my concept of a two-valued investor's strategic choice set and apply their formal theory of motion to this example of an attitude space. The result is a new theory of the business cycle, based on shifts in investors' strategic emphasis (expansionary versus rationalizing investments). The theory is not only a significant extension of neoclassical microeconomics, since it operationalizes the decision process of the industrial investor, but also stands up well in empirical testing when applied to aggregate industrial change in West Germany, 1950-1980.

(3) Weidlich and Haag even take on the tantamount problem of disarmament and survival of mankind, which is threatened by the deadlock rivalry of the superpowers. Again, they analyze the interplay of both sides from their vintage point of view, namely, interactions in attitude space as the sources of inertia and change. Given the two socio-configurations, they show that in quantitative terms their interaction generates a complex pattern of possible developments, some of them leading to positive and cooperative global patterns, others triggering chain reactions that may lead into disaster. In particular, application of their new methodology shows, over and above common knowledge, that certain attitude changes, even if they appear threatening, do not harm the status quo, whereas seemingly well-directed intentions may provide counteractive reactions destabilizing the system. Thus, they contribute significantly to the present controversy over stabilizing versus destabilizing defense strategies.

The scope of Weidlich and Haag's theory is truly impressive. Its major impact, however, can be expected in the field of Schumpeterian economics, as it pertains to socio-econornic issues of governance. Some economists regard Schumpeter's grand design as unfinished. J. Niehans (in Kyklos, 1981), called Schumpeter "a tragic figure in the history of economic analysis" because of his inability to transform his visions of innovation and socio-economic change into an analytical model. Weidlich and Haag's contribution is a major step in the direction of developing such an overall model. At any rate, it is a significant achievement in several of the subdisciplines that provide concepts and methods used in human resource management.

Gerhard O. MENSCH 